\title{
Da totalidade objetiva à realidade subjetiva: breves notas sobre verdade e liberdade em Hegel $^{1^{\star}}$
}

\section{From an objective reality to a subjective reality: a brief reflection about truth and freedom in Hegel}

RESUMEN: El sistema filosófico creado por Georg Wilhelm Friedrich Hegel es considerado una de las obras más importantes en la historia de la filosofía occidental. Desde su creación y desarrollo, no es posible encontrar un intento que se acerque de los esfuerzos del idealista alemán en la comprensión de la realidad en su estructura lógica, epistémica y sistemática. Por lo tanto, el presente texto intenta articular las ideas principales de Hegel con las categorías de la verdad y la libertad, enunciando sus relaciones con la importancia de la interpretación sistemática en la obra del filósofo.

PALABRAS CLAVE: HEGEL; VERDAD; LIBERTAD; INTERPRETACIÓN SISTEMÁTICA

\begin{abstract}
The philosophical system created by Georg Wilhelm Friedrich Hegel is considered one of the most important works in the history of the western philosophy. Ever since it's creation and development, there was not an attempt that could overcome the efforts of the german idealist in the understanding of reality in it's logical, epistemic and sistematic structure. Therefore, the present text intends to articulate Hegel's main ideas with the categories of truth and freedom, enunciating its relations with the importance of the sistematic interpretation in the philosopher's work.
\end{abstract}

KEYWORDS: HEGEL; TRUTH; FREEDOM; SISTEMATIC INTERPRETATION

[1] * Comunicação apresentada ao VI Congreso Internacional de la SocIEDAd EspaÑola de Estudios sobre Hegel Verdad y Libertad en Hegel y Schelling; Universidad de Málaga, 18-20 de Septiembre de 2017. 


\section{ConsideraÇões INICIAIS}

$\mathrm{O}$ sistema filosófico proposto por Georg Wilhelm Friedrich Hegel revolucionou por completo a história da filosofia ocidental vivida até o seu tempo, não havendo, desde então, nenhuma tentativa de estruturação lógica, epistêmica ou sistemática que superasse seus esforços na empreitada rumo a compreensão da realidade ${ }^{1}$. Os conceitos que dizem respeito às categorias de verdade e liberdade ocupam papel significativo dentro dessa construção, sendo necessário abordar esses respectivos aspectos para compreender a magnitude dos trabalhos do filósofo. Assim sendo, pretende-se aqui articular algumas das categorias do sistema hegeliano com tais ideias, buscando elucidar, a partir de relações existentes, tanto a leitura sistemática do pensamento de Hegel, quanto os caminhos interpretativos que verdade e liberdade auxiliam a traçar.

\section{I.1. AS PREMISSAS HISTÓRICAS}

Inicialmente, é preciso abordar o contexto histórico no qual o filósofo se insere, visto que o período de formação do pensamento de Hegel foi responsável por instituir uma série de mudanças radicais no campo sociopolítico da civilização humana. O final do século XVIII e o início do século XIX marcaram a história da civilização ocidental (romano-germânica ${ }^{2}$ ) com uma série de revoluções e rupturas que influenciaram tanto os escritos teóricos políticos do autor quanto seu sistema filosófico e o entendimento do Espírito de seu tempo.

"Em 1789, explodiu a Revolução Francesa entre o entusiasmo dos intelectuais mais iluminados de todas as nações europeias. Rapidamente, porém, a Revolução apresentou reviravolta que colheu todos de surpresa. Em 1792, foi derrubada a monarquia na França e proclamada a República. Em 1793, o rei foi condenado ao patíbulo. A partir de agosto de 1793, teve início o Grande Terror, que produziu milhares de vítimas. (...) A ascensão napoleônica, que culminou em 1805 com a proclamação do Império, e as campanhas militares, que puseram a Europa sob ferro e fogo e subverteram toda a estrutura política e social do velho continente,

[1] Em sua tese de cátedra da Universidade Federal de Minas Gerais, o jusfilósofo mineiro Joaquim Carlos Salgado indaga: Por que Hegel? Sua resposta retrata a importância do filósofo para o pensamento do ocidente: "Porque em Hegel terminam os esforços da cultura ocidental para pensar a totalidade num sistema de saber. E o momento de maturidade do período histórico que permitiu esse pensar sistemático é a chave de compreensão do mundo contemporâneo." SALGADO, Joaquim Carlos. A idéia de justiça em Hegel. São Paulo: Edições Loyola, 1996, p. 25.

[2] Para compreender melhor o sentido da divisão entre a civilização ocidental e a civilização extremo-ocidental (anglo-saxã), sugere-se HORTA, José Luiz B.; RAMOS, Marcelo Maciel. Entre as Veredas da Cultura e da Civilização. Revista Brasileira de Filosofia, São Paulo, Instituto Brasileiro de Filosofia, v. 233, p. 235-264, 2009. 
instaurando novo despotismo, fizeram ruir por terra todos os resíduos de esperanças iluministas que ainda restavam. "3

É preciso rememorar, ainda, o momento vivido pelo povo alemão ${ }^{4}$. Nas palavras de Walter Jaeschke:

“(...) en esta época tiene lugar la disolucíon del -imperio germânico- (1802) y la conseguiente reordenacíon política de Alemania, llevada a cabo, em parte por Napoleón, y em parte, despúes de su derrota, por el Congreso de Viena (1815). Ciertamente, tal reordenacíon estuvo más marcada por la continuidad que la evolucíon francesa; pero los Estados que surgieron de ella eran marcadamente diferentes de los de la época prerrevolucionaria, aunque la mayoría de ellos no se basaran en una Constitución escrita. "5

Tendo vivido em meio a tempos tão revolucionários e marcantes no caminhar da humanidade, não é de surpreender que seja possível encontrar nas obras de Hegel uma perspectiva profundamente histórica, cuja manifestação é evidente em diversas características de seu pensamento. Seja nas reflexões a respeito do desenvolvimento do Espírito ao longo da História, no entendimento dialético de que estágios pretéritos de uma entidade se suprassumam ${ }^{6}$ em seu momento atual ou em atribuições como as das astúcias da razão, da Filosofia da História e etc., as reflexões históricas vividas pelo ocidente estão intrinsecamente ligadas aos textos hegelianos. ${ }^{7}$

[3] REALE, Giovanni; ANTISERI, Dario. História da Filosofia, V. 5 - Do Romantismo ao Empiriocriticismo. São Paulo: Paulus, 2005, p.3-4.

[4] "El pueblo alemán, relativamente marginado de tanto de la revolucíon comercial e industrial burguesa como de su correspondiente batalla político-social más violenta, parece obligado a abocarse a pensar la revolución, a extender sus potencialidades, esperanzas y sueños al marco totalizador de la historia universal del género humano. ” MAYOS, Gonçal Solsona. Ilustracíon y Romanticismo. Barcelona: Herder Editorial, 2004, p. 14.

[5] JAESCHKE, Walter. Hegel. La conciencia de la modernidade. Madrid: Akal, 1998, p. 5.

[6] Termo introduzido a partir da tradição brasileira, na seara dos introdutores e tradutores do pensamento hegeliano Henrique Cláudio de Lima Vaz e Paulo Meneses, que propõem, para os termos em alemão Aufheben e Aufhebung, respectivamente, suprassumir e suprassunção.

[7] "É bem verdade que antes de Hegel o pensamento europeu já flertasse com a possibilidade de instituição de uma Filosofia da História, quer em Voltaire, quer em Kant ou em Herder. No entanto, nenhum destes autores foi capaz de construir, como Hegel o pretendeu, um genuíno saber filosófico sobre a história - elevando a história a objeto posto à reflexão da filosofia. A Europa madura, entre ciosa de seu papel frente à humanidade e ciente das especificidades da civilização ocidental, já se indagava a respeito da possibilidade de interpretação de uma história humana comum à totalidade da existência (inspirada pelas escatologias judaicas e cristãs), de um destino comum à humanidade. Nesse contexto é que surgirão as primeiras possibilidades de compreensão filosóficas da história, as quais, como sabemos, encontrarão solene morada na filosofia 


\section{I.2. AS PREMISSAS FILOSÓFICAS}

Passadas as relações e os contextos históricos, podemos avançar para o cenário de discussões filosóficas que se encontram no tempo de Hegel. Para tal, é necessário apresentar um recorte temporal que recolha os inúmeros pensamentos e as diversas correntes filosóficas que estão em embate nas obras do pensador em questão. A época demarcada entre a segunda década do século XVIII e os primeiros trinta anos do século XIX parece abarcar um conjunto primordial de conhecimentos que culminam no cenário que aqui se busca retratar.

"Por lo demás, en ese tiempo y en ese territorio se darían - como si se tratara de un campo de batalla com deserciones y hasta paso al otro bando - todos esos movimientos que por lo común parecen estar perfectamente roquelados con sus nombres y sus fechas: la Ilustracíon propriamente dicha (...), el Sturm und Drang 8(...), el - clacismo - (...), el criticismo o la filosofía transcendental kantiana, el idealismo alemán y el romanticismo (...). Puede ser que esas divisiones y clasificaciones tengan alguna utilidad didáctica, pero a la verdad confunden más que aclaran; no sólo se pierde así la continuidad de los problemas, y aun desarollo vital de individuos señalados (...), sino que resultan inexplicables (...) las - recurrencias -y resurgimientos de autores o doctrinas que no - deberían - estar allí (...). "”

Seja a respeito das correntes acima elucidadas, ou até mesmo da dicotomia entre cultura e natureza ${ }^{10}$, Hegel lança vistas para uma filosofia marcada pela

hegeliana. Hegel articula a relação da História e da Filosofia de modo absolutamente original, proclamando que a História outra coisa não é que a Filosofia, e a Filosofia outra coisa não é, que História. " HORTA, José Luiz Borges. Hegel, paixão e diferença. In: OLIVEIRA JÚNIOR, José Alcebíades de, COSTA, Renata Almeida da, HORTA, José Luiz Borges (coords.). Direito, Estado e Idealismo Alemão. Florianópolis: CONPEDI, 2015. p. 80.

[8] Movimento datado entre os anos de 1770 e 1780 ocorrido no que viria a se tornar a Alemanha, responsável pelo início da superação total do Iluminismo e pela afirmação do Romantismo. Tem como principais características a predileção pelas paixões e pelos sentimentos fortes, a caracterização da natureza como força onipotente e análoga as criações da mentalidade humana e o sentimento pátrio exaltador da liberdade. Pensadores como Goethe e Herder são considerados como os primeiros a produzir obras sob essa ótica. Tradução literal: tempestade e ímpeto.

[9] DUQUE, Félix. Historia de la Filosofía Moderna. Madrid: Ediciones Akal, 1998, p. 16.

[10] "O que marcou de forma indelével a civilização ocidental foi ter se dado a consciência da cisão ôntica a que se submete o ser humano na sua vida social concreta: de um lado, a necessidade do conhecer teórico da natureza que ele precisa dominar para estar-aí, de outro, o mundo da cultura em que se impõe a ordem normativa para a sua conduta, (...) que tem por finalidade não apenas o seu estar-aí, mas estar-aí como no seu mundo, na sua casa (zu Hause), como livre (bei sich). " SALGADO, Joaquim Carlos. A ideia de justiça em Hegel. São Paulo: Edições Loyola, 1996, p. 15. 
cisão e pela crítica, e busca, a partir dessas categorias, reconciliar dialeticamente a filosofia do ocidente mediante um único sistema filosófico.

\section{O SISTEMA FILOSÓFICO HEGELIANO}

Para compreendermos os esforços inicialmente referenciados, é preciso avaliar o papel da Filosofia como saber. Nesse sentido, essa tarefa não se dissocia de uma concepção sistêmica. Para Hegel, todo seu conhecimento consiste, essencialmente, no conhecimento da totalidade. Esse, por sua vez, só é possível se construído de forma sistemática, de forma a se chegar na compreensão de Absoluto.

"O mesmo desenvolvimento do pensar, que é exposto na história da filosofia, expõe-se na própria filosofia, mas liberto de exterioridade histórica - puramente no elemento do pensar. O pensamento livre e verdadeiro é em si concreto, e assim é idéia, e em sua universalidade total é a idéia ou o absoluto. A ciência [que trata] dele é essencialmente sistema, porque o verdadeiro, enquanto concreto, só é enquanto desdobrando-se em si mesmo, e recolhendo-se e mantendo-se junto na unidade - isto é, como totalidade; e só pela diferenciação e determinação de suas diferenças pode existir a necessidade delas e a liberdade do todo. "11

Além de tê-lo como objeto, a ciência do Absoluto necessita que esse tome conhecimento de si próprio. Nesses moldes, a noção de Espírito surge como a verdade em infinito processo de movimento, que está sempre atuando e se realizando ${ }^{12}$.

O Espírito, ao refletir-se em si mesmo, apresenta um momento circular que pode ser dividido em três: o do ser em si, o do ser fora de si e o do ser em si e para si. Essa divisão acaba por traduzir o pensamento sistemático de Hegel, visto que sua filosofia será dividida na medida dessas três categorias:

“Como não se pode dar uma representação prévia, geral de uma filosofia pois somente o todo da ciência é a exposição da idéia, assim também sua divisão só pode ser concebida a partir dessa exposição; a divisão é como a idéia, da qual

[11] HEGEL, Georg Wilhelm Friedrich. Enciclopédia das ciências filosóficas em compêndio. \$14. São Paulo: Loyola, 1995, p. 55.

[12] "O espírito tem para nós a natureza por sua pressuposição, da qual ela é a verdade e, por isso, seu [princípio] absolutamente primeiro. Nessa verdade, a natureza desvaneceu, e o espírito se produziu como idéia que chegou ao seu ser-para-si, cujo objeto, assim como o sujeito, é o conceito. Essa identidade é a negatividade absoluta, porque o conceito tem na natureza sua objetividade externa consumada, porém essa sua extrusão é suprassumida, e o conceito tornou-se nela idêntico a si mesmo. Por isso o conceito só é essa idealidade enquanto é retornar da natureza. ” Ibidem, \$381, p. 15. 
tem de tirar uma antecipação. A idéia porém se comprova como o pensar pura e simplesmente idêntico a si mesmo, e esse como atividade de se opor a si mesmo para ser para si; e nesse Outro, somente junto a si mesmo. Assim a ciência se divide em três partes: I - A lógica, a ciência da idéia em si e para si; II - A Filosofia da Natureza, como a ciência da idéia em seu ser-outro; III - A Filosofia do Espírito, enquanto idéia que em seu ser-outro retorna a si mesma. "13

\section{II.1 A DIALÉTICA ${ }^{14}$}

Talvez estejam na dialética as principais chaves para a compreensão do pensamento de Hegel e da totalidade de seu sistema. Revista inúmeras vezes durante a história da filosofia ${ }^{15}$, a categoria foi aprimorada no pensamento do filósofo, passando de método do pensar filosófico para lógica do real, ou seja, para a estrutura e desenvolvimento intrínsecos ao objeto de estudo (totalidade). É ela a responsável por exprimir o movimento, a atualização e a suprassunção do Espírito mediante o real. Assim sendo, a dialética possui seus três momentos:

“a) o lado abstrato ou do entendimento; b) o dialético ou negativamente-racional; c) o especulativo ou positivamente racional. Esses três lados não constituem três partes da Logica, mas são momentos de todo [e qualquer] lógico-real, isto e, de todo conceito ou de todo verdadeiro em geral. Eles podem ser postos conjuntamente sob o primeiro momento - o do entendimento - e por isso ser mantidos separados uns dos outros; mas, desse modo, não são considerados em sua verdade. A indicação que aqui é feita sobre as determinações do lógico - assim como a [sua] divisão - está aqui somente numa forma antecipada e histórica. "16

[13] Ibidem, $\$ 18$, p. 58.

[14] 'Dialektik deriva do grego dialektiké (techné), que vem de dialegesthai, 'conversar', e era originalmente a 'arte da conversação', mas foi usada por Platão para designar o método filosófico correto. ” INWOOD, Michael. Dicionário Hegel. Rio de Janeiro: Jorge Zahar, 1997, p. 99.

[15] "A dialética, como sabemos, é descoberta dos antigos. Nascida no âmbito da escola eleática (sobretudo com Zenão), alcançara seu ponto culminante com Platão. Na época moderna, Kant retomou-a em sua Crítica da razão pura, mas reduzira-a desenvolvimento sistemático de antinomias destinadas a permanecer insolúveis, privando-a, portanto, de valor cognoscitivo. A redescoberta dos gregos permitiu o relançamento da dialética como forma suprema de conhecimento, como Platão já fizera. (E, entre outras coisas, cabe precisamente a Hegel o mérito de ter reconhecido os diálogos chamados "dialéticos de Platão, ou seja, o Parmênides, o Sofista e o Filebo, que antes dele eram deixados de lado, mas que depois dele, em consequência, passaram a ser reconhecidos como fundamentais.) " REALE, Giovanni; ANTISERI, Dario. História da Filosofia, V. 5 - Do Romantismo ao Empiriocriticismo. São Paulo: Paulus, 2005, p.105-106.

[16] HEGEL, Georg Wilhelm Friedrich. Enciclopédia das ciências filosóficas em compêndio. \$79. São Paulo: Loyola, 1995, p. 139. 
O primeiro momento, o entendimento, é constituído de categorias distintas e definidas. A razão dialética (negativa), ou segundo momento é caracterizada pelo surgimento das contradições. Daí é desvelado o terceiro estado, o especulativo, que nada mais é se não a suprassunção dos momentos anteriores, a unidade dos opostos elevada a um plano superior. Portanto,

"A dialética, do ponto de vista de Hegel, explica todo o movimento e toda a mudança, tanto no mundo quanto em nosso pensamento sobre ele. Também explica por que as coisas, assim como os nossos pensamentos, apresentam uma coesão sistemática entre si. " 17

Realizadas as breves exposições anteriores, podemos avançar para as temáticas da verdade e da liberdade.

\section{II.2 A VERDADE}

Se tomarmos a palavra verdade em sentido estrito dentro do pensamento de Hegel, encontraremos uma série de utilizações que, por mais que façam sentido em uma construção filosófica específica, não podem ser tomadas em um plano interpretativo que se coloque à altura das proposições trabalhadas em conjunto pelo filósofo. Para que essa colocação seja possível, é preciso diferenciar algumas das aplicações nos trabalhos do autor.

Os usos dados no $\$ 24$ da Enciclopédia das Ciências Filosóficas, por exemplo, trazem uma série de reflexões sobre um sentido filosófico específico de verdade, que remeteria a adequação de um objeto com seu conceito.

“Chamamos comumente 'verdade' a concordância de um objeto com nossa representação. Temos nesse caso, como pressuposição, um objeto ao qual deve ser conforme nossa representação sobre ele. No sentido filosófico, ao contrário, verdade significa - [se for] expressa em geral abstratamente - concordância de um conteúdo consigo mesmo (...). Fala-se, por exemplo, de um verdadeiro amigo; e se entende, com isso, um amigo cuja maneira-de-agir é conforme ao conceito de amizade (...). Nesse sentido, um mau Estado é um Estado não verdadeiro, e o mau e o não-verdadeiro, em geral, consistem na contradição que tem lugar entre a determinação ou o conceito, e a existência de um objeto. "18

Tanto a utilização anterior quanto outras, por exemplo, a das relações de identidade (em sentido estrito) entre pensamento e ser e entre subjetivo e objetivo, possuem sua reflexão dentro de uma construção filosófica mais ampla

[17] INWOOD, Michael. Dicionário Hegel. Rio de Janeiro: Jorge Zahar, 1997, p. 101.

[18] HEGEL, Georg Wilhelm Friedrich. Enciclopédia das ciências filosóficas em compêndio. $\$ 24$ A.2. São Paulo: Loyola, 1995, p. 82. 
acerca do sentido de verdade. Essa, por sua vez, está intrinsecamente ligada a ideia de Absoluto, visto que, para Hegel, somente as categorias do Absoluto, da ideia e do Espírito são estritamente verdadeiras.

"A consciência-de-si, [que é] assim a certeza de que suas determinações tanto são objetivas, determinações da essência das coisas, quanto são seus próprios pensamentos, é a razão; razão que, enquanto é essa identidade, não é somente a substância absoluta, mas a verdade como saber. Com efeito, ela tem aqui por determinidade própria, por forma imanente, o conceito puro existente para si mesmo: [o] Eu, a certeza de si mesmo como universalidade infinita. Essa verdade que sabe é o espírito. "19

A filosofia como busca pelo conhecimento da totalidade tem, por consequência, a pretensão de entendimento e de contato com aquilo que se denomina real, em outras palavras, verdadeiro. Nesse sentido, também é válida a reflexão de Hegel proposta no Prefácio de sua obra Filosofia do Direito: " O que é racional, isto é efetivo; e o que é efetivo, isto é racional. " 20 Em outras palavras, o real possui (dialeticamente em relação ao sujeito) a racionalidade incutida em sua essência, visto que a razão humana é capaz de refletir sobre esse aspecto. A estrutura do pensar só poderia estar de acordo com a estrutura do pensável ${ }^{21}$.

Torna-se interessante, então, utilizarmos das últimas provocações para as reflexões que se seguirão entre verdade e liberdade. Antes, porém, é necessário trabalhar a segunda categoria mencionada.

[19] Ibidem, \$438, p. 209.

[20] HEGEL, Georg Wilhelm Friedrich. Filosofia do Direito. Prefácio. Trad. Paulo Meneses et al. São Leopoldo, RS: UNISINOS, 2010, p. 41.

[21] "Do outro lado, é igualmente importante que a filosofia esteja bem consciente de que seu conteúdo não é outro que o conteúdo originariamente produzido - e produzindo-se - no âmbito do espírito vivo, e constituído em mundo, [mundo] exterior e interior da consciência; [e entrada] que o conteúdo da filosofia é a efetividade. Chamamos experiência a consciência mais próxima desse conteúdo. Uma consideração sensata do mundo já distingue o que, no vasto reino do ser-aí exterior e interior, é só fenômeno, [é] transitório e insignificante - e o que em si verdadeiramente merece o nome de efetividade. Enquanto a filosofia só difere segundo a forma de outro conscientizar-se desse único e idêntico conteúdo, é necessária sua concordância com a efetividade e a experiência; e mesmo essa concordância pode considerar-se como uma pedra de toque, ao menos exterior, da verdade de uma filosofia; assim como é para se considerar como o fim último e supremo da ciência o suscitar, pelo conhecimento dessa concordância, a reconciliação da razão consciente-de-si com a razão essente com a efetividade. " HEGEL, Georg Wilhelm Friedrich. Enciclopédia das ciências filosóficas em compêndio. \$6. São Paulo: Loyola, 1995, p. 44. 


\section{II.3 A LIBERDADE}

"A vontade livre e efetiva é a unidade do espírito teórico e do espírito prático: vontade livre que é para si mesma como vontade livre, enquanto ela se suprassumiu o formalismo, a contingência e a limitação de conteúdo prático rotineiro. Pelo suprassumir da mediação, que estava aí contida, essa vontade é a singularidade imediata, posta por si; mas que ao mesmo tempo é depurada na determinação universal, na liberdade mesma. Essa determinação universal, a vontade a tem como seu objeto e meta enquanto ela se pensa, sabe esse conceito seu, é vontade enquanto livre inteligência. "22

Pode-se entender a liberdade em Hegel a partir da totalidade de seus significados políticos e sociais, porém trabalhada em dois aspectos: arbítrio e intelecto. O primeiro deles consistiria no meio-termo entre a vontade ligada aos impulsos naturais e a vontade considerada livre em si e para si. O segundo, por sua vez, teria como resultado a partir de seu desenvolvimento o conteúdo, objeto e fim da liberdade. Portanto, é a atividade do pensar que possibilita o ser livre.

"O pensamento é a um só tempo universal e livre. Pensar é realizar a liberdade, porque é estar em si mesmo, não alienar-se no exterior, no outro; é bei sich sein ${ }^{23}$, estar consigo no seu próprio elemento. "24

Outro aspecto sob o qual é necessário se debruçar na reflexão sobre a liberdade diz respeito ao Espírito objetivo, ou o Espírito que se realiza coletivamente. Nele, é preciso ressaltar a importância do $E s t a d o^{25}$, na realização e efetivação do ser livre:

"O Estado é a efetividade da ideia ética - o espírito ético enquanto vontade substancial manifesta, nítida a si mesma, que se pensa e s sabe e realiza o que sabe e na medida que sabe. No costume, ele [o Estado] tem sua existência imediata e, na autoconsciência do singular, no saber e na atividade do mesmo, a sua existência mediada, assim como essa, mediante a disposição do espírito nele [no Estado],

[22] Ibidem, \$481, p. 274.

[23] Tradução literal: estar consigo mesmo.

[24] SALGADO, Joaquim Carlos. A ideia de justiça em Hegel. São Paulo: Edições Loyola, 1996, p. 469.

[25] "Es ist der Gang Gottes in der Welt, dass der Staat ist. ” HEGEL, G.W.F. Grundlinien der Philosophie des Rechts; uber Naturrecht und Staatswissenchaft im Grundrisse. 3. ed. Stuutgart: Fr. Frommanns Verlag, 1952, p. 336 [\$ 258, Zusatz]. (Tradução literal: O Estado é o caminhar de Deus no Mundo) 
como sua essência, seu fim e seu produto de sua atividade, tem a sua liberdade substancial. "26

\section{Articulações ENTRE VERDADE E LIBERDADE}

Tendo como horizonte as noções já referenciadas de verdade como o Absoluto da ideia e do Espírito em constante movimento e de liberdade como autodeterminação da razão ou como conteúdo, objeto e fim do intelecto, podemos refletir sobre os possíveis encontros de tais categorias.

Em princípio, é perceptível que o processo evolutivo da tomada de consciência subjetiva na cultura ocidental é permeado pela ideia de liberdade. A história do ocidente é conduzida pelo vetor racional de sua busca, juntamente com a tentativa de efetivação dessa. Esse processo é intimamente conectado com o caminhar e o movimento do Espírito rumo ao Absoluto. A partir daí, então, conclui-se uma das relações da realidade objetiva, da verdade com o caminhar em busca do ser livre. É a partir da negação do não-subjetivo, ou seja, da realidade objetiva, que o sujeito tem a noção de si próprio e de que integra a unidade entre as inúmeras consciências-de-si. Somente assim ele pode ser considerado livre.

Tendo em si incutida a racionalidade, o sujeito tem em si também sua liberdade a partir do momento que age racionalmente. Logo, ao ter consciência da efetividade do real verdadeiro e de vice-versa, ele percorre parte imprescindível do caminho do Espírito rumo ao Absoluto.

Podemos reiterar ainda a importância do Estado em toda a temática em questão, visto que sua construção configura a implementação intelectual máxima da sociedade na busca para a realização da liberdade. É nele que é trazido à tona o último estágio de reconhecimento do sujeito em relação aos demais outros, por meio da experiência concreta, material e espiritual. Não podemos nos esquecer, por fim, do papel da história nessas reflexões, ao passo que essa é o desdobramento da dialética entre os Estados e mais, é o desdobramento do Espírito no tempo.

\section{CONSIDERAÇÕES FINAIS}

Com base em todas considerações aqui propostas, é possível afirmar que o conceito de liberdade em Hegel não se separa da razão subjetiva nem da consciência-de-si, mas pelo contrário, só se faz possível a partir dessa tomada de consciência eminentemente dialética. A totalidade objetiva e a realidade subjetiva teriam, então, dentro de suas contradições, afirmações e suprassunções,

[26] HEGEL, Georg Wilhelm Friedrich. Filosofia do Direito. \$257. Trad. Paulo Meneses et al. São Leopoldo, RS: UNISINOS, 2010, p. 229. 
um papel fundamental dentro do sistema filosófico hegeliano, principalmente no que tange à verdade e à liberdade.

“'Um grande homem condena os humanos a explica-lo. 'Essa frase de Hegel se aplica a ele mesmo mais que a ninguém. No entanto, a grandeza singular de seu pensamento levou muitos intérpretes a se condenarem na tentativa de explicar a Hegel, porque não souberam ou não quiseram considerar e analisar justamente o que torna a filosofia hegeliana excepcional: sua sistematicidade real. Sistematicidade real e não apenas aparente. "27

\section{REFERÊNCIAS BibliográfiCAS}

Duque, FéLIx. Historia de la Filosofía Moderna. Madrid: Ediciones Akal, 1998.

Hegel, G.W.F. Grundlinien der Philosophie des Rechts; uber Naturrecht und Staatswissenchaft im Grundrisse. 3. ed. Stuutgart: Fr. Frommanns Verlag, 1952. Hegel, Georg Wilhelm Friedrich. Enciclopédia das ciências filosóficas em compêndio. 3 V. Trad. Paulo Menezes e José Machado. São Paulo: Loyola, 1995.

Hegel, Georg Wilhelm Friedrich. Filosofia do Direito. [Linhas Fundamentais da Filosofia do Direito; ou Direito natural e Ciência do Estado em compêndio. ] Trad. Paulo Meneses et al. São Leopoldo, RS: UNISINOS, 2010.

Horta, José Luiz B.; Ramos, Marcelo Maciel. Entre as Veredas da Cultura e da Civilização. Revista Brasileira de Filosofia, São Paulo, Instituto Brasileiro de Filosofia, v. 233, p. 235-264, 2009.

HorTa, JosÉ LuIz Borges. Hegel, paixão e diferença. In: OLIVEIRA JÚNIOR, José Alcebíades de, COSTA, Renata Almeida da, HORTA, José Luiz Borges (coords.). Direito, Estado e Idealismo Alemão. Florianópolis: CONPEDI, 2015.

Inwood, Michael. Dicionário Hegel. Rio de Janeiro: Jorge Zahar, 1997.

JAeschKe, Walter. Hegel. La conciencia de la modernidade. Madrid: Akal, 1998. Mayos, GonçAL. Ilustracion y Romanticismo. Barcelona: Herder Editorial, 2004.

Reale, Giovanni; Antiseri, Dario. História da Filosofia, V. 5 - Do Romantismo ao Empiriocriticismo. São Paulo: Paulus, 2005.

Salgado, Joaquim Carlos. A ideia de justiça em Hegel. São Paulo: Edições Loyola, 1996.

[27] BOURGEOIS, Bernard in HEGEL, Georg Wilhelm Friedrich. Enciclopédia das ciências filosóficas em compêndio. Apresentação. São Paulo: Loyola, 1995, p. 375. 
